\title{
Celso Furtado, transdisciplinar e contemporâneo
}

[Celso Furtado, transdisciplinary and contemporary

ORGANIZAÇÃO DO DOSSIÊ

Alexandre de Freitas Barbosa ${ }^{\mathrm{I}}$

André Botelho

Vera Alves Cepêda ${ }^{3}$

Alexandre Macchione Saes 4

Recebido em 22 de fevereiro de $202 I$

Aprovado em Io de março de $202 I$

BARBOSA, Alexandre de Freitas; BOTELHO, André; CEPÊDA, Vera Alves; SAES, Alexandre Macchione. Celso Furtado, transdisciplinar e contemporâneo. Revista do Instituto de Estudos Brasileiros, Brasil, n. 78, p. I7-24, abr. 202I.

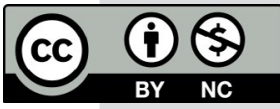

DOI: https://doi.org/Io.II6o6/issn.23I6-90IX.vIi78pI7-24

I Universidade de São Paulo (USP, São Paulo, SP, Brasil).

2 Universidade Federal do Rio de Janeiro (UFRJ, Rio de Janeiro, RJ, Brasil).

3 Universidade Federal de São Carlos (UFSCar, São Carlos, SP, Brasil).

4 Universidade de São Paulo (USP, São Paulo, SP, Brasil). 
O dossiê "Celso Furtado, transdisciplinar e contemporâneo" da Revista do Instituto de Estudos Brasileiros (RIEB) é resultado da parceria acadêmica entre seus organizadores. Se a proposta surgiu motivada pelo centenário de nascimento de Furtado, desde o início se pretendeu fugir do tom encomiástico.

A rememoração e atualização da obra e vida de Celso Furtado expressa dois movimentos principais. O primeiro, do reconhecimento da importância que a produção intelectual brasileira tem como parte ativa na autopercepção da identidade nacional, na compreensão de nossa formação e de nossos velhos/novos dilemas e na produção de diagnósticos da estrutura social, material e cultural, que influenciaram, direta ou indiretamente, as escolhas e as trajetórias da nossa vida coletiva.

O segundo ângulo é o reconhecimento da importância da reflexão e da ação de Furtado no fluxo desse contexto, em virtude do seu legado intelectual potente em profundo diálogo com outras interpretações do país que lhe antecederam e sucederam.

O conjunto de artigos que compõem este dossiê orbita entre as várias faces desse reconhecimento: ora eles incidem sobre momentos específicos do trabalho furtadiano e seu diálogo epocal; ora sobre a dinâmica diacrônica da produção e da correlação de suas teses com o contexto em movimento; ora se observa a arquitetura das formulações e do processo de laboração intelectual do autor por meio dos temas abordados, das suas interlocuções teóricas e da adoção de métodos de análise para obtenção de respostas; ora ainda se observam a recepção e os efeitos de suas teses, em seu tempo ou ao longo do tempo, no âmbito do debate nacional (ponto de origem dos dilemas éticos, intelectuais, políticos e pessoais de Furtado), ou em sua necessária interlocução e forte impacto no debate mundial (quer no plano teórico, quer no epistemológico, geopolítico ou geoeconômico).

Tratar de Furtado e de sua obra ao longo dos Ioo anos da vida do autor é refletir sobre as mudanças profundas que se gestaram na sociedade, na cultura e nas instituições brasileiras desde I920 até hoje, e que estão enraizadas nos propósitos, formas e resultados da reflexão do autor. Há como que uma mescla de fortuna (as condições históricas que circunscreviam a experiência vivida de Furtado) com virtú (o hercúleo esforço intelectual, político e ético do autor ao eleger como telos de sua existência a compreensão do caudaloso rio da história que produzira as sociedades subdesenvolvidas, armando-se de ferramentas capazes de promover a sua transformação). 
Assim, a obra de Furtado absorve, reflete e inflete o caleidoscópio dos múltiplos e combinados aspectos da vida social, apreendidos e compreendidos em uma dimensão racional também multifacetada e devolvida por meio de alternativas intelectuais e políticas à disposição da sociedade.

Isso explica o porquê do dossiê estar ancorado em torno de dois eixos básicos: a característica transdisciplinar do legado furtadiano, que explica a ampla circulação das teses do autor em domínios distantes da economia (talvez área mater, mas não alma mater de Furtado); e sua contemporaneidade, que não se restringe ao tempo que viveu, atuou e combateu pelo desenvolvimento nacional, atualizando-se para outros tempos (o nosso), revestida de novas roupagens e utopias, pois o seu método é vigoroso e assim o exige.

Não à toa, as numerosas celebrações do centenário do mais importante economista brasileiro realizadas ao longo dos últimos meses reuniram, por meio das telas dos computadores (efeito da pandemia de covid-I9), gerações de economistas, cientistas sociais e intelectuais brasileiros e latino-americanos. As atividades percorreram todo o território nacional e vários eventos internacionais foram organizados.

Furtado foi celebrado também com a publicação de livros organizados para sua homenagem ${ }^{5}$. Dois deles merecem destaque: Diários intermitentes: I937-2002, lançado em 20I9, e Correspondência intelectual de Celso Furtado (I949-2004), a ser publicado neste ano de 202I. Os dois livros foram organizados cuidadosamente por Rosa Freire d'Aguiar e trazem a público um conjunto de documentos valiosos que abrem novas frentes de pesquisa sobre o autor.

Os periódicos não deixaram por menos. Recebendo uma grande quantidade de artigos publicados em suas edições, alguns periódicos também organizaram dossiês exclusivos para discutir o centenário de Furtado. A revista Cadernos do desenvolvimento, do Centro Internacional Celso Furtado de Políticas para o Desenvolvimento, publicou "Ioo anos de Celso Furtado" (2020); a Revista de Ciências Sociais da Universidade Federal do Ceará, por sua vez, ofereceu o "Centenário de Celso Furtado" (2020); "Celso Furtado, I920-2020: diálogo e interdisciplinaridade" é o tema do dossiê de História Econômica eł História de Empresas (202I), da Associação Brasileira de Pesquisadores em História Econômica.

O dossiê "Celso Furtado, transdisciplinar e contemporâneo", publicado agora na RIEB, se soma ao conjunto de estudos que surgiram em torno do centenário do maior economista e um dos mais importantes intérpretes do Brasil.

Entendemos que a originalidade da nossa contribuição se revela pela reunião de trabalhos que nascem da perspectiva transdisciplinar aplicada a movimentos particulares da sua análise em várias temporalidades. Nesse sentido, merecem destaque a dinâmica de produção da obra; a trajetória do autor; a trajetória da obra e das teses do autor; o repertório, o léxico e os temas; os efeitos e as permanências no campo intelectual; os efeitos e as permanências no campo político; os efeitos e as permanências no campo cultural; o estilo intelectual; o método e as matrizes teóricas, entre outros aspectos.

A chave transdisciplinar, aberta para a imaginação criadora e transformação do

5 Conferir: Quintela et al. (2020), Sousa et al. (2020a; 2020b; 2020c), Leitão et al. (2020), Saes; Barbosa (202I). 
mundo, é o que permite pensar os temas contemporâneos por meio das ideias de Celso Furtado. Esse exercício está plenamente presente no artigo de abertura de nosso dossiê. O embaixador Rubens Ricupero, com “Celso Furtado: pensador global”, retoma a trajetória do economista, dando ênfase para o olhar de Furtado sobre as relações internacionais, por meio de Brasil: a construção interrompida, reiterando o papel fundamental da autonomia dos centros internos de decisão para a construção de projetos de futuro.

O dossiê possui mais dez contribuições que podem ser agrupadas em três grandes eixos analíticos. O primeiro eixo examina as contribuições basilares de Celso Furtado, investigando sua formação como economista e sua interpretação sobre o Brasil e a encruzilhada do subdesenvolvimento. O segundo eixo acompanha a trajetória de suas ideias, mobilizadas em diferentes contextos históricos, debatendo os limites do liberalismo e a centralidade do papel do Estado e do planejamento, num contexto de subdesenvolvimento e dependência. Por fim, o terceiro eixo expande a leitura do economista Celso Furtado para seus diálogos transdisciplinares, uma interpretação incapaz de ser contida na rígida e hermética teoria econômica.

Como abertura do primeiro eixo, Carlos Mallorquin, em "El desafío de la sustitución de importaciones de las categorías occidéntricas: Celso Furtado”, retoma a produção do economista entre o período da Comissão Econômica para a América Latina (Cepal) e o golpe militar para indicar como a concepção estruturalista de sua obra, ao negar os enunciados da teoria econômica neoclássica, abriu espaço para uma crítica teórica e metodológica que hoje pode ser caracterizada como uma das bases do pensamento decolonial.

Elisa Klüger amplifica, no artigo "Celso Furtado: por uma ciência econômica iconoclasta e inconformista", os argumentos de Carlos Mallorquin ao avaliar a "ciência econômica iconoclasta e inconformista" de Celso Furtado. Ao percorrer a construção do método e da interpretação do autor, a autora destaca a originalidade do pensamento-ação de Furtado: como iconoclasta, ao romper com os paradigmas neoclássicos, e como inconformista, com seu projeto de transformação social.

Alexandre de Freitas Barbosa discute a obra mais conhecida e, possivelmente, mais debatida de Celso Furtado: Formação econômica do Brasil. Por meio da clássica obra, o artigo "Celso Furtado, intérprete do Brasil" produz um diálogo entre o economista e os chamados "intérpretes do Brasil" para reafirmar a posição de Furtado no panteão dos demiurgos do Brasil, como quer Francisco de Oliveira. Ao reiterar a relevância da obra de Furtado, e do seu método, para compreender o Brasil, o autor tece diálogos com Caio Prado Jr., Gilberto Freyre e Sérgio Buarque de Holanda, sugerindo que a obra clássica de Furtado deve ser lida em par com Desenvolvimento $e$ subdesenvolvimento e A pré-revolução brasileira.

Carmen Felgueiras, por sua vez, embarca nas viagens de juventude de Celso Furtado, interrogando seus registros deixados nos Diários intermitentes. Ao percorrer os espaços de sociabilidade, nacionais e internacionais de Celso Furtado, a autora de "Pouco mais do que uma viagem de turismo': as viagens de juventude de Celso Furtado" apresenta o percurso de alargamento da vivência, da reflexão e da perspectiva de mundo do autor. Tratar a subjetividade como relação social e histórica permite não apenas redimensionar a relação entre indivíduo e sociedade, como também projetar novas percepções sobre a obra de Furtado. 
Inaugurando o segundo eixo analítico, Vera Alves Cepêda e Gustavo Louis Henrique Pinto examinam, em "A teoria do subdesenvolvimento e o projeto desenvolvimentista de Celso Furtado: reflexões sobre os limites do liberalismo", as críticas de Furtado às leis do mercado e à teoria econômica neoclássica, indicando como a adoção dos postulados liberais operou na construção do subdesenvolvimento, impedindo a sua superação. Na tese furtadiana, a intervenção do Estado, mediante um planejamento racional, é uma peça decisiva para a superação do subdesenvolvimento, dissociada, como reforçam os autores, da tradição autoritária brasileira. $\mathrm{O}$ texto destaca como o projeto desenvolvimentista de Furtado afasta-se das premissas liberais apresentando uma nova função para a defesa dos princípios democráticos.

Renato Nataniel Wasques dá prosseguimento à tarefa de investigar o papel do Estado na interpretação de Celso Furtado. Num sobrevoo pelas seis décadas de pensamento de Furtado, Wasques avalia no artigo "O pensamento de Celso Furtado sobre Estado e planejamento" como os textos de juventude, as obras cepalinas e de intervenção política da primeira metade da década de I960, assim como as obras do período do exílio e aquelas do período de uma economia que se globalizava, mobilizaram os conceitos e as práticas do planejamento e do Estado como coordenador e orientador de decisões econômicas estratégicas.

Ainda como parte do segundo eixo, no artigo "Celso Furtado, intérprete da dependência”, o conceito de dependência é analisado por Rômulo Manzatto e Alexandre Macchione Saes. Se Celso Furtado é reconhecido como um dos formuladores do estruturalismo latino-americano, os autores defendem que o economista deve ser também elencado entre os pioneiros da teoria da dependência que pautaram parte do debate teórico da região nos anos 1970. Por meio da mediação das obras de Celso Furtado com seus interlocutores do período inicial do exílio, os autores apresentam o processo de revisão de suas ideias, momento em que a interdisciplinaridade assume dimensão central em sua obra.

Por fim, o terceiro eixo discute diretamente alguns dos diálogos transdisciplinares de Celso Furtado, intelectual que partiu da ciência econômica para construir sua interpretação, que interage e assimila, de maneira inovadora, a história, a sociologia, a ciência política e a cultura.

Assim, Roberto Pereira Silva se volta ao estudo da tese de doutorado de Celso Furtado para entender como o autor mobilizou os conceitos e os métodos das ciências sociais para produzir aquele que é reconhecido como o trabalho mais histórico do autor. Como indica Roberto em "A história vista pelas lentes das ciências sociais: uma interpretação de Economia colonial no Brasil nos séculos XVI e XVII, de Celso Furtado”, ainda que se valendo de fontes primárias e dos relatos de viajantes do Brasil colonial, as análises sobre a economia e a sociedade da colônia são também influenciadas pela renovação historiográfica em curso na França, deixando marcas profundas em sua interpretação sobre a história econômica brasileira.

César Bolaño, por sua vez, resgata em "Celso Furtado e a antropologia: notas para o diálogo entre economia política e estudos culturais" o diálogo de Furtado com a antropologia, trazendo elementos dos estudos culturais britânicos de Stuart Hall. Como afirma Bolaño, Furtado foi o autor do estruturalismo latino-americano que mais se valeu da antropologia e da economia da cultura. Para ele, Furtado confiava 
na atuação na consciência crítica da classe média brasileira para formular um projeto nacional de desenvolvimento.

O último artigo do dossiê, "Leituras em competição (à distância): dois experimentos de pesquisa a partir da obra de Celso Furtado", de autoria de Antonio Brasil Jr., Lucas Carvalho e Karim Helayel, apresenta um estudo cientométrico sobre a produção de Celso Furtado e do fluxo de buscas de verbetes da Wikipédia. O texto demonstra como Furtado permanece como uma referência importante para diferentes gerações. A abrangência dos temas tratados e a atualidade das ideias do economista podem ser entendidas como as principais razões da permanência de Furtado no debate econômico e social contemporâneo.

Neste número da RIEB que contém o dossiê Celso Furtado, o mestre aparece também na seção Documentação. O artigo "Volta às fontes batismais: Celso Furtado e a profecia da Sudene”, escrito por Darlan Praxedes Barboza e Elisabete Marin Ribas, apresenta "uma pequena mas significativa amostra dos materiais inéditos do acervo pessoal de Celso Furtado" no IEB, detendo-se sobre os itens documentais referentes à Sudene. Os autores articulam a trajetória de Furtado anterior à Sudene e mostram como a sua atuação no comando da agência de desenvolvimento cumpriu um papel estratégico de formação e inspiração para a juventude da época.

Além de mapear o debate em torno da Sudene e a sua condução pelo também “jovem” Furtado, são apresentados no texto os principais adversários do projeto de transformação do Nordeste, que ia muito além da transformação econômica. Com base nessa documentação, pode-se refutar de uma vez por todas a afirmação leviana de alguns economistas, para quem Furtado não teria se dedicado ao tema da educação. Uma das prioridades da Sudene era justamente eliminar o analfabetismo e ampliar a oferta de pessoal técnico, como o demonstra o plano estrutural de educação, de I962, elaborado em cooperação com os governos estaduais, a Usaid-Aliança para o Progresso e o MEC.

O dossiê aproveita-se da onipresença de Celso Furtado - que segue aparecendo novinho em folha em livros inéditos organizados e apresentados por Rosa Freire d'Aguiar ou nas coletâneas sobre sua trajetória e pensamento - para oferecer ao leitor duas resenhas.

Rafael Pacheco Mourão, em "Celso Furtado, os Diários intermitentes e o Brasil: as memórias de um intelectual público", procura apontar como as "facetas íntimas" de Furtado vêm à luz nos seus diários, e de maneira diferente da sua obra autobiográfica, revelando, sem filtro, os "processos de reavaliação e reposicionamento" durante a sua longa trajetória. Conforme o autor, temos diante de nós o ser humano, humanista e ético homem público, recontando os fatos que lhe parecem essenciais, realizando interpretações e traçando perfis de intelectuais e homens públicos com os quais contracenou durante cerca de 50 anos. A resenha é cuidadosa ao mostrar o seu ângulo de visão sobre a conjuntura, por vezes acompanhado de sínteses estruturais robustas, auxiliando o leitor na busca de novas chaves de compreensão e pesquisa.

A segunda resenha, "Destecer os 60 anos de Formação econômica do Brasil", dedica-se à obra Celso Furtado e os 60 anos de Formação econômica do Brasil, organizada pelos professores Alexandre Macchione Saes e Alexandre de Freitas Barbosa. O livro é fruto do seminário realizado em 2019 por meio da parceria entre a Biblioteca 
Brasiliana Guita e José Mindlin, o Instituto de Estudos Brasileiros da Universidade de São Paulo (IEB/USP) e o Centro de Pesquisa e Formação do Sesc. Gustavo Louis Henrique Pinto traça os vários eixos que cruzam os I6 artigos que compõem o livro, destacando os distintos horizontes de interpretação abertos pelo clássico ontem e hoje. Os artigos cobrem as várias dimensões da obra de Furtado, detendo-se sobre a sua vinculação ao gênero de formação, as pontes entre a economia e a história, bem como entre teoria, método e projeto político, e indicando a atualidade do livro e o potencial de pesquisa no arquivo de Celso Furtado no IEB.

Percebemos que as releituras possíveis da obra e da trajetória de Furtado carregam as marcas da transdisciplinaridade e da contemporaneidade, presentes na formação de sucessivas gerações, e ainda fundamentais para a compreensão deste país tão distinto - e ao mesmo tempo tão semelhante - daquele que obcecou Furtado desde o início de sua carreira.

No labirinto do presente, Furtado se reapresenta como guia, com sua imaginação criadora e seu método certeiro. Pensar a partir do mestre, como vários de nós o fazemos, ou procuramos fazer, não significa, porém, repetir fórmulas - que necessariamente se atualizaram, mas mantiveram, se não reiteraram, as tendências excludentes de uma sociedade conservadora como a brasileira. Ao contrário, significa compreender e atuar sobre nossa contemporaneidade de maneira transdisciplinar e mediante a responsabilidade com o futuro. Esse é o legado de Celso Furtado que desejamos compartilhar com as leitoras e os leitores em seu centenário.

\section{SOBRE OS AUTORES}

ALEXANDRE DE FREITAS BARBOSA é professor de História Econômica e Economia Brasileira do Instituto de Estudos Brasileiros da Universidade de São Paulo (IEB/USP) e bolsista Produtividade CNPq (categoria 2).

afbarbosa@usp.br

https://orcid.org/oooo-0002-0493-7488

\footnotetext{
ANDRÉ BOTELHO é professor do Departamento de Sociologia e do Programa de Pós-graduação em Sociologia e Antropologia da Universidade Federal do Rio de Janeiro (UFRJ), Pesquisador (IC) do CNPq e Cientista do Nosso Estado da Faperj. andrebotelho@digirotas.com.br https://orcid.org/oooo-00oI-68I5-9040
} 
VERA ALVES CEPÊDA é professora do Departamento de Ciências Sociais, do Programa de Pós-Graduação em Ciência Política (PPGPol) e do Programa de PósGraduação em Sociologia (PPGS) da Universidade Federal de São Carlos (UFSCar). veracepeda@ufscar.br https://orcid.org/0000-0002-I4I9-0090

ALEXANDRE MACCHIONE SAES é professor do Departamento de Economia da Faculdade de Economia, Administração e Contabilidade da Universidade de São Paulo (FEA/USP) e bolsista Produtividade CNPq-2. alexandre.saes@usp.br https://orcid.org/0000-0003-4274-I993

\section{REFERÊNCIAS}

CADERNOS do Desenvolvimento. Dossiê roo Anos de Celso Furtado. Rio de Janeiro: Centro Internacional Celso Furtado de Políticas para o Desenvolvimento, v. I5, n. 26, jan.-jun. 2020.

FURTADO, Celso. Diários intermitentes: I937-2002. Organização, apresentação e notas de Rosa Freire d’Aguiar. Prefácio de João Antonio de Paula. São Paulo: Companhia das Letras, 2019.

FURTADO, Celso. Correspondência intelectual de Celso Furtado (I949-2004). Organização, apresentação e notas de Rosa Freire d'Aguiar. Prefácio de Luiz Felipe de Alencastro. São Paulo: Companhia das Letras, $202 \mathrm{I}$.

HISTÓRIA Econômica \& História de Empresas. Dossiê Associação Brasileira de Pesquisadores em História Econômica, v. 24, n. I, 202I.

LEITÃO, Cláudia de Souza et al. (org.). Anais do Seminário Ioo anos de Celso Furtado: que desenvolvimento queremos para o Brasil?. Fortaleza: Prefeitura de Fortaleza, 2020.

QUINTELA, Adroaldo et al. (org.). Celso Furtado: os combates de um economista. São Paulo: Fundação Perseu Abramo/Expressão Popular, 2020.

REVISTA de Ciências Sociais. Dossiê Centenário de Celso Furtado. Periódico do Departamento de Ciências Sociais e do Programa de Pós-Graduação em Sociologia da Universidade Federal do Ceará, v. 5I, n. I, 2020.

SAES, Alexandre Macchione; BARBOSA, Alexandre de Freitas. Celso Furtado e os 60 anos de Formação econômica do Brasil. São Paulo: Senac/BBM, 202I.

SOUSA, Cidoval Morais de; THEIS, Ivo Marques; BARBOSA, José Luciano Albino (org.). Celso Furtado: a esperança militante. V. I (Interpretações). Campina Grande: Eduepb, $2020 a$.

SOUSA, Cidoval Morais de; THEIS, Ivo Marques; BARBOSA, José Luciano Albino (org.). Celso Furtado: a esperança militante. V. 2 (Depoimentos). Campina Grande: Eduepb, $2020 b$.

SOUSA, Cidoval Morais de; THEIS, Ivo Marques; BARBOSA, José Luciano Albino (org.). Celso Furtado: a esperança militante. V. 3 (Desafios). Campina Grande: Eduepb, 2020c. 